\title{
ABISMOS INOMINÁVEIS E NOVAÇÃo: QUeSTÕEs SOBRE O FinAL De ANÁLISE ${ }^{1}$
}

Sonia Leite ${ }^{2}$

\section{RESUMO}

Freud em "Análise terminável e interminável" indica que ao final de uma análise encontra-se um rochedo, o insuperável rochedo da castração, tanto para as mulheres como para os homens. Lacan, por sua vez, fala da presença de uma pedra no caminho em direção ao final da análise, encontro do real que, ao contrário de Freud, considera passível de ser transposto. A travessia da fantasia supõe, assim, o embaraço diante da crueza de algo que se apresenta como intransponível. Encontro com o inominável que comporta duas facetas: por um lado, o silenciamento do sujeito , diante do traumático e, por outro, aquilo que, incitando o ultrapassamento do plano das identificações, permite o aparecimento de um sentido novo, de uma novação. Uma nova-ação que afirma um paradoxo que demanda a invenção ao final de cada experiência analítica e que compromete o sujeito com a transmissão daquilo que é essencial à psicanálise.

PalavRas-Chave: final de análise; real; desejo do analista; perda-de-si; dessubjetivação

\footnotetext{
1 Trabalho apresentado no VII Encontro Nacional e VII Colóquio Internacional do Corpo Freudiano Escola de Psicanálise que ocorreu em São Luis, em 2017, e cujo tema foi Uma janela para o Real: a fantasia na psicanálise.

2 Psicanalista. Doutora em Psicologia Clinica PUC/RIO. Editora responsável da Revista Latinoamericana de Psicopatologia Fundamental e da Seção Arte, Literatura e Cultura da mesma revista. Coordenadora de Ensino do Corpo Freudiano Escola de Psicanálise Seção RJ. E- mail: soniacleite@uol.com.br.
} 
"O que é vertigem? Medo de cair? Mas porque temos vertigem num mirante cercado por uma balaustra sólida? Vertigem não é o medo de cair, é outra coisa. É a voz do vazio de baixo de nós, que nos atrai e nos envolve, é o desejo da queda do qual nos defendemos aterrorizados." (M. Kundera, 2008)

\begin{abstract}
"Nessa reviravolta em que o sujeito vê soçobrar a segurança que extraia da fantasia em que se constitui, para cada um, sua janela para o real, o que se percebe é que a apreensão do desejo não é outra senão a de um des-ser." (Lacan, 1967)
\end{abstract}

Freud, no artigo de 1937, "Análise terminável e interminável", levanta algumas importantes indagações: Existe um término natural para cada análise? É possível em geral levar uma análise até o final? O artigo deixa uma impressão inicial de pessimismo, pelo fato de colocar em destaque as dificuldades e obstáculos para o fim de uma análise.

Ao interrogar o que faz barreira ao caminho da cura, Freud destaca três pontos principais: a) o efeito dos traumas; b) a intensidade das pulsões; c) a alteração do eu. Afirma que o mais importante deles é a intensidade pulsional e a possibilidade de uma certa sujeição (Bändigung) da mesma. Em outras palavras, a pulsão não mais seguiria um caminho próprio para a satisfação, mas, estaria de algum modo acessível ao eu e ao processo de simbolização.

Chama a atenção para o aspecto econômico, pelo fato de que a decisão de todo conflito dependeria, fundamentalmente, dos fatores quantitativos em jogo, isto é, da força pulsional em suas relações com o eu. Considera que é por isso que algumas situações inesperadas da vida, tais como, o adoecimento, o esgotamento ou a perda de um ente querido, provocam a fragilização do eu e das identificações colocando em risco a estabilidade psíquica. Nessas situações, a intensidade dos estímulos pode ser de tal forma aumentada que traria, como consequência, o que nomeio de "destituição traumática".

É importante diferenciar a destituição psíquica, que faz parte da travessia de uma psicanálise, ou seja, uma destituição consentida, sustentada pela transferência, e a destituição que se impõe pelas situações da vida. Tais situações podem, inclusive, algumas vezes, provocar a necessidade de uma nova etapa de análise, fato que é possível deduzir do texto freudiano. Mas, tanto Freud quanto Lacan, ressaltam que a mudança ao final de uma análise se localiza, especialmente, no modo como o sujeito vive a pulsão (Lacan, 1964), em outras palavras, vive aquilo que é irredutível e que se repete. 
É a temática da repetição que parece ter levado Freud a utilizar o conectivo e que expressa a conjunção no título "Análise terminável e interminável”. A utilização de tal conectivo lógico exige que as duas proposições sejam consideradas simultaneamente verdadeiras.

É a compulsão a repetição que atualiza a experiência mostrando a insistência da cadeia significante e, também, do impossível que aí retorna. Repetição e insistência remetem assim ao "interminável", ao sem fim da análise. Nesse sentido, o que se atualiza é a expressão do real enquanto impossível, mas, também, a infinita tentativa de representar isso que não cessa de insistir.

Freud chama a atenção para a tendência à inércia que percorre a experiência analítica e faz com que o analisante sempre esteja disposto a conformar-se com o que denomina de uma tramitação imperfeita (FREUD, 1937, p. 234). Tal inércia retrata um modo próprio do indivíduo se defender. Cada pessoa, como indica, não utiliza mais do que uma seleção de mecanismos de defesa “(...) mas estes se fixam em seu ego, tornando-se modalidades regulares de reação de seu caráter, as quais são repetidas durante toda a vida, sempre que ocorre uma situação semelhante à original" (FREUD, 1937, p.270) .

São esses mecanismos que vão surgir como resistência ao tratamento e ao término da análise. Freud, também, faz referência a "adesividade da libido", que pode ser lida com Lacan, nos termos de uma fixação no gozo, que em alguns casos dificulta, ainda mais, o desligamento em relação aos objetos primários. Por outro lado, nos lembra, que em algumas pessoas, também pode ocorrer uma extrema mobilidade da libido, de um objeto a outro, que traz como efeito o que denomina de uma impermanência dos resultados analíticos. Afirma que, no primeiro caso, é como trabalhar com a "pedra dura" e, no segundo, com o "gesso macio". Dificuldades que apesar de distintas fazem barreira a direção de uma cura.

Outra fonte de resistência é associada à relação entre pulsões de vida e de morte, especialmente, a presença do masoquismo que faz o sujeito aderir a doença e ao sofrimento e que pode assumir a forma de uma reação terapêutica negativa. Nesse último caso, muitas vezes o efeito é a paralização do tratamento, pois, como Freud indica no artigo "O problema econômico do masoquismo", de 1924, o que se apresenta é uma necessidade de punição que torna inócua todas as intervenções do analista (LIMA; LEITE, 2011). 
Pode-se considerar que a principal fonte de resistência à análise e, como Freud indica, a causa última do conflito psíquico, é a presença da pulsão de morte. Que com Lacan, assume a forma de um encontro com o real inominável. Momento em que faltam as palavras, assim como, também, a imagem de si, do eu e do corpo próprio.

Caberia, nesse sentido, considerar que aquilo do qual cada um se defende, não é nada mais e nem menos do que de sua própria perda. A experiência da perda do objeto seria, então, uma maneira de interpretar e recobrir a experiência da perda de si mesmo. Reencontro com abismos inomináveis. Perda radical, que Catherine Millot (2001) descreve como cisão brutal, que reduz o eu a um ponto derisório no universo.

O eu se envelopa construindo fronteiras a partir das identificações com o Outro, delimitando, assim, um lugar psíquico habitável para a existência. Uma análise, por sua vez, convida o sujeito em direção a uma travessia que desnuda o eu, promovendo a desconstrução dos seus pontos de sustentação, convocando a um luto de si, a partir de onde algo novo poderá emergir.

Freud conclui o texto citado, afirmando que é o rochedo da castração (roca de base), na forma de um repúdio à feminilidade, tanto nos homens, quanto nas mulheres, aquilo que impede o final de uma análise. Afirma, aqui, que é o tema do amor ao pai, sustentáculo derradeiro, aquilo que é recusado dos dois lados. É essa questão que podemos reportar a discussão presente no artigo freudiano de 1919, "Bate-se numa criança", sobre a fantasia fundamental, cujo axioma encoberto é "eu sou amado pelo pai".

A feminilidade, um dos nomes do real, é aquilo que aponta para uma situação limite que convoca o sujeito à criação ex nihilo. É a partir daí que Lacan faz avançar a teoria e a clínica, considerando que uma análise é finita, ou seja, deve ter seu momento de concluir, pois, sempre haverá um resto impossível de saber. E é tal fato que conduz o analisante a um saber-fazer com o real impossível.

\section{O Luto Na AnÁlise: SuJeito Suposto Saber E Des-Ser}

Freud vai considerar em 1917, que o luto ocorre quando se produz a perda de algo de suma importância para o indivíduo e que pode ser tanto, uma ideia, uma abstração, um fracasso amoroso, assim como, a morte real do objeto. Lacan, por sua vez, no seminário 10, sobre a angústia, indica que o luto é uma tarefa que se repete, tendo-se em vista que a perda do objeto amado remete a algo mais primário e inacessível que se reporta ao objeto enquanto impossível. 
Nesse sentido, a análise é "um trabalho com tempos de atravessamento, análogo ao luto, uma vez que esta implica passar por operações que incluem a função da perda como necessária na constituição do sujeito." (MARISCAL, 2009). Ou seja, trata-se de um processo de desprendimento em relação aos objetos, que exige tempo e energia fato que implica o psicanalista nesse processo, a partir do manejo da transferência. Manejo que Freud (1912) considera como a única dificuldade, realmente séria, com a qual o analista vai se deparar ao longo de sua prática.

Para manejar a transferência em prol da análise é necessário que o analista responda de um lugar que inclua a diferença radical entre o Outro e o outro, a partir de onde a fala do analisante possa se constituir. Segundo Lacan (1967), a experiência analítica só pode se desenvolver ao preço do constituinte ternário que é aquele introduzido no discurso que se instaura: o sujeito suposto saber, pivô da transferência, efeito da estrutura analítica.

Considerar que a transferência é o amor, significa reconhecer que existe uma demanda dirigida ao psicanalista que passa a ocupar o lugar de ideal do eu, ponto a partir do qual o sujeito se vê como amável, como eu ideal. O silencio do analista, a não resposta as demandas que surgem nesse processo, faz surgir a dupla dimensão da falta: a falta de significante no Outro e a falta do objeto no desejo.

A estrutura da experiência analítica se refere, essencialmente, ao seu começo e ao seu final. Freud a compara a um jogo de xadrez com aberturas, desenlaces e que inclui inúmeras combinações durante seu processo. O sujeito suposto saber, nesse sentido, é a estrutura da abertura de uma psicanálise.

\section{Mas E O Final De Uma Análise?}

A análise da transferência, a partir do desejo do analista, consiste em revelar que não há, nesse sentido, sujeito suposto saber. Lacan ressalta que é o analista que deve se tornar um resíduo da operação analítica, pois, o único objeto a ser proposto à transferência é o objeto a. Se, por um lado, a transferência coloca o amor na berlinda, Lacan o apresenta como um modo de captação que protege o sujeito da angústia, além de mantê-lo no desconhecimento daquilo que lhe falta.

$\mathrm{Na}$ medida em que a demanda tem como resposta o desejo (enigmático) do analista, o plano das identificações pode ser ultrapassado. Como indica Lacan (1964), esse mais-além se define pela relação e pela distância do objeto a minúsculo ao I maiúsculo idealizante da identificação. 
Sintetizando, a manobra da transferência está submetida às eventualidades da prática, e depende do desejo do analista. A operação do ato analítico deve reduzir esse sujeito suposto saber à função de objeto a. Ou seja, o analista terá sido o sujeito suposto saber quando sua função se reduz à do $a$, esse dejeto, esse resíduo do saber. Trata-se, aqui, da operação de des-ser.

A destituição subjetiva, que é a operação correlata ao des-ser do sujeito suposto saber é aquilo que ocorre quando há o reconhecimento da opacidade do objeto pulsional que sempre escapa a apreensão pelo sujeito. Tal processo impõe uma mudança radical na posição subjetiva permitindo que o analisante se depare com o núcleo de sua economia pulsional, para além da fantasia, pois o que se reencontra é a inconsistência do Outro que a fantasia encobria.

\section{Abismos Comuns, Inomináveis E O Fim De AnÁlise}

Em 2001, foi publicado pela Gallimard, o livro "Abîmes ordinaires", da psicanalista Catherine Millot, que, recentemente, tive acesso. Trabalho delicado em que a autora revela algumas passagens de sua história pessoal, atravessadas por momentos importantes de sua análise com Lacan.

Me surpreendi com algumas descrições, especialmente, aquelas em que ressalta o que denomina como a "perda de si" que marca o encontro com a dissolução do eu. Momentos que reportam aos escritos de Lacan relativos à travessia da fantasia, que direciona o final da análise.

A autora nos brinda com a narração de um certo tipo de vivência que tivera na infância, e no início da juventude, e que lhe conduziram a buscar a análise. Revela que aquilo que procurava, quando demanda o tratamento a Lacan, era reencontrar o vazio que essas experiências Ihe haviam proporcionado. Vazio fundamental que havia Ihe permitido o acesso a uma estranha liberdade que teria, em algum momento da vida, se perdido.

"Eis, aqui, minha vida mais secreta", nos confidencia Millot (2001, p. 11), logo no início do seu livro.

A seguir relata três momentos principais, em que se encontra diante do inominável arrebatador.

O primeiro momento, ocorre aos seis anos quando havia se mudado com a família para Budapeste (Hungria). A pedido de alguém, sobe a escada para o segundo andar da casa aonde a família havia acabado de se instalar. No meio do caminho, 
sente, subitamente, o mundo se esvaziar, se tornando um verdadeiro deserto. "Nada antes, nada depois, nada de pais, ninguém", nos revela. Durante alguns segundos, solidão absoluta. Considera, que não seria apropriado falar "eu", porque esse "eu" era sem qualquer qualidade, um ponto de existência nua na escada vazia. E "isso", enfatiza, "não é possível de se esquecer".

O segundo momento, seis anos mais tarde, ocorre em circunstâncias parecidas em Helsinki (Finlândia). Cidade com uma língua estranha e aonde o sol, algumas vezes, não se põe antes da meia noite. Estava entre caixas de papelão numa peça de apartamento mobiliado, no centro da cidade. E, de repente, mais uma vez, como pontua, experimenta o vazio, marcado pela abertura para o infinito do espaço sideral. Atravessada por uma cisão brutal tem a sensação de ser aspirada, vertiginosamente, deixando para trás um "eu" que não era mais nada.

Tomada de pavor, se agarra ao seu nome próprio, num apelo radical de si mesma. O nome próprio é um traço intraduzível, único, como indica Lacan (1961-62) e que lhe permitiu, mais uma vez, se localizar na realidade humana comum.

A terceira vez, ocorre quando estava entrando na vida adulta. Tinha recebido a convocação para assumir um posto, como professora, na Província, em uma cidade distante da vida familiar. Mais uma vez, precisa enfrentar o que denomina de um exílio forçado, o que lhe causa muita angústia. Parte em um carro usado, e com uma carteira de motorista nova, pela chamada "Estrada da Morte", itinerário que atravessa a França de Leste a Oeste (RCEA-Route Centre-Europe Atlantique). Antes de chegar ao destino um pneu fura e o carro lhe foge ao controle. Em sentido contrário, vem um caminhão que por pouco não lhe tira a vida.

Essa situação de quase encontro com a morte lhe traz, mais uma vez, a ausência absoluta de referências, porém, com uma característica a mais. A falta de proteção experimentada lhe conduz, simultaneamente, a um sentimento de milagre da vida carregada de uma sensação de liberdade, até então, desconhecida. Um grande vazio se instala, mas um "vazio" que denomina de "reparador" e que faz nascer uma nova experiência espaço-temporal. A angústia dá lugar a uma paz infinita acompanhada de uma sensação de renascimento. Nesse momento se interroga: "Teria eu consentido com a minha perda?"

O fato é que essa experiência que denomina de graça infinita, aos poucos desaparece, dando lugar novamente a angústia. E é tal desaparecimento que promove a busca da análise com Lacan quando visava se livrar do que chama de a 
"sua patologia". O que a move nessa decisão foi o fato de ter escutado em alguns seminários proferidos por Lacan, pontos que faziam eco ao que aspirava reencontrar: não há Outro do Outro, travessia da fantasia, destituição subjetiva, des-ser.

Durante a sua análise, um pouco temerosa e insegura, relata ao analista as experiências relativas ao vazio e à morte quando, então, escuta de Lacan, duas intervenções que considera fundamentais no seu processo.

A primeira, quando este lhe indica que seus relatos tinham relação, com as experiências místicas e com o que Heidegger havia descrito no livro "Serenidade", sobre a importância de se recuperar o pensamento meditativo, ou o deixar-ser. A segunda intervenção lhe deixa atônita, Lacan afirma: "o que você conheceu ali é o amor."

Interessante lembrar que no seminário 11, "Os quatro conceitos fundamentais da psicanálise", Lacan faz referência ao fato de que uma psicanálise nos abre a possibilidade da experiência de um amor sem limite e que é essa experiência que está subjacente a emergência do desejo do analista (LEITE, 2017).

Millot considera que foi o signo de um reconhecimento advindo do analista aquilo o que Ihe permitiu seguir com a análise na direção de uma apropriação dos abismos que atravessaram de forma disruptiva a sua vida.

O fato, conclui a autora, é que na vida cotidiana o vazio se oculta, se dissimula na medida em que uma ausência fundamental é recoberta pela fantasia inconsciente, sustentando os sintomas. Reencontrar esse vazio, apropriando-se dele, nos abre a possibilidade radical de presentificação da vida e de sua recriação.

O que está na origem da busca de uma análise é a presença do mal estar sintomático. A demanda de amor inscrita na transferência e instaurada no início dessa caminhada, é aquilo que permite a sustentação da travessia da fantasia e que ao fim do caminho confronta o sujeito com um vazio fundamental. Considero, nesse sentido, que o relato da autora pode ser lido como parte da passagem do sintoma ao sinthome, em outras palavras, do processo que lhe permitiu a identificação ao synthome, enquanto particularidade subjetiva, reduzida ao seu núcleo mais real (LACAN, 1975).

Diante de um limite incontornável algo pode se abrir para o que Lacan denomina de "novação" (Lacan, 1955; 1970). Significante que condensa o novo e a ação. Novação que envolve o ato de fazer e fazer-se e que só se torna possível porque diante do abismo só resta ao falasser abismar-se, renovando a surpresa do existir: Sou? 


\section{REFERÊNCIAS}

FREUD, Sigmund. Edição Standard Braasileiras das Obras Psicológicas Completas de Sigmund Freud. Rio de Janeiro:Imago, 1977

(1912). Recomendações aos médicos que exercem a psicanálise. In: ESB,

RJ:Imago, v.XII.

(1917[1915]). Luto e melancolia. In: ESB, RJ:Imago, v.XIV.

(1919). Uma criança é espancada. Uma contribuição ao estudo da origem das perversões sexuais. In: ESN, Jorge Zahar Ed, v.XVII.

(1937). Análise terminável e interminável. In: ESB, RJ:Imago, v. XXIII.

KUNDERA, Milan. A insustentável leveza do ser. São Paulo:Companhia de Bolso, 2008.

LACAN, Jacques (1955). A coisa freudiana. In: Escritos. RJ:Jorge Zahar Ed., 1998.

Proposição de 9 de outubro de 1967 sobre o psicanalista da Escola. In:

Outros Escritos. RJ: Jorge Zahar Ed, 2001.

(1961-62)Seminário livro 9 A identificação. Centro de Estudos Freudianos do

Recife. Tradução Ivan Corrêa e Marcos Bagno. Publicação não comercial, out 2003.

(1962-63). Seminário 10 A angústia. RJ:Jorge Zahar Ed., 2005.

(1964). Seminário 11 Os quatro conceitos fundamentais da psicanálise.

RJ:Jorge Zahar Ed., 1988.

(1970). Radiofonia. In: Outros escritos. RJ:Jorge Zahar Ed., 2003.

(1975-76). Seminário 23. O sinthoma. RJ:Jorge Zahar Ed., 2007.

LIMA, Mariana; LEITE, Sonia. O masoquismo e o problema econômico em Freud. Psicanálise \&Barroco em revista. V.9, n. 2:161-177, dez 2011.

LEITE, Sonia. A paixão segundo G.H. e o amor sem limite. Caliban Revista de Artes, Letras e Ideias. dez 2017. https://revistacaliban.net/

MARISCAL, Diana Lídia. Sobre o luto. Escola da Letra Freudiana - Da experiência psicanalítica - ano XXVIII, n.41, 2009.

MILLOT, Catherine. Abîmes ordinaires. Paris:Gallimard, 2001. 


\title{
Nameless Abysses And Novation: Questions About ThE END Of ANALYSIS
}

\begin{abstract}
Freud on his book 'Analysis Terminable and Interminable' indicates that at the end of an analysis a rock is found, the unsurpassed rock of castration for women, and for men. Lacan, in his turn, speaks about the presence of a stone on the way towards the end of the analysis, the meeting of the real that, as opposed to Freud, Lacan considers liable to be transposed. The crossing of fantasy supposes, thus, the embarrassment before rawness of something that presents itself as insurmountable. The meeting with the unnameable that comports two aspects: on the one hand, the silencing of the subject and, on the other hand, inciting the surpassing of the plan of the identifications, that which allows the appearing of a new sense, a novation. A new action that states a paradox which demands the invention at the end of each analytical experience and that commits the subject to the transmission of what is essential to psychoanalysis.
\end{abstract}

KEYWORDS: end of analysis; real; analyst's desire; the loss of self; desubjectivation 


\section{Les Abîmes InNOMmables Et Novation: Questions SuR LA FIN DE L'ANALYSE}

\section{RÉSUMÉ}

Freud dans "Analyse terminée et analyse interminable" indique qu'à la fin d'une analyse on trouve un rocher, l'insurmontable rocher de la castration pour les femmes, et pour les hommes. Lacan, à son tour, parle de la présence d'une pierre sur le chemin vers la fin de l'analyse, rencontre du réel que, au contraire de Freud, Lacan estime passible d'être transposé. La traversée de la fantaisie suppose, ainsi, l'embarras face à la crudité d'une chose qui se présente comme insurmontable. La rencontre avec l'innommable qui comporte deux facettes : d'une part, le faire taire du sujet, face au traumatisme et, d'autre part, ce qui, incitant le dépassement du plan d'identification, permet l'apparition d'un sens nouveau, d'une novation. Une nouvelle action qui affirme un paradoxe qui exige l'intervention à la fin de chaque expérience analytique et qui engage le sujet dans la transmission de ce qui est essentiel à la psychanalyse.

MotS-ClÉs : fin de l'analyse; réel; le désir de l'analyste; la perte de soi; désubjectivation 
RECEBIDO EM 10/12/2019

APROVADO EM 07/07/2020

(C) 2020 Psicanálise \& Barroco em revista

http://www.seer.unirio.br/index.php/psicanalise-barroco/index

revista@psicanaliseebarroco.pro.br

Programa de Pós-Graduação em Memória Social — UNIRIO

Memória, Subjetividade e Criação

www.memoriasocial.pro.br/proposta-area.php 